\title{
Analysis of Calsium (Ca) and Potassium (K) Levels in Candlenut Shells (Aleurites moluccana Willd)
}

\author{
*Megawati T. H. Romu, Siti Nuryanti \& Sitti Aminah \\ Pendidikan Kimia/FKIP - Universitas Tadulako, Palu - Indonesia 94119 \\ Received 27 December 2019, Revised 31 January 2019, Accepted 27 February 2020 \\ doi: 10.22487/j24775185.2020.v9.i1.pp58-62
}

\begin{abstract}
Candlenut shell (Aleurites moluccana Willd) is a waste produced from processing candlenut plants with a fairly hard texture. The use of candlenut shells as fertilizer, especially in Central Sulawesi, has not been done so much. The aim of this study was to determine the levels of calcium $(C a)$ and potassium $(K)$ in candlenut shells. Calcium and potassium levels were determined using an atomic absorption spectrophotometer (AAS). The results show that the average calcium level in the candlenut shell is $0.315 \pm 0.09 \%$, while the average potassium level is $0.090 \pm 0.01 \%$. The results of $C a$ and $K$ in candlenut shell are expected to be used as raw material for fertilizer production.
\end{abstract}

Keywords: Candlenut shell (Aleurites moluccana Willd), calcium, potassium, atomic absorption spectrophotometer (AAS)

\section{Pendahuluan}

Tanaman kemiri (Aleurites mollucana Willd) merupakan jenis tanaman yang mudah ditanam, cepat tumbuh dan tidak begitu banyak menuntut persyaratan tempat tumbuh (Sunanto,1994). Tanaman kemiri hidup di daerah tropis dan subtropis sehingga dapat ditanam di daerah dataran rendah maupun dataran tinggi, baik di tanah yang subur maupun tanah yang kurang subur jika ditanam dengan baik pada kelembapan tanah yang cukup (Suwarto dkk., 2014).

Tanaman kemiri merupakan tanaman industri, sebab produk yang dihasilkan dapat dipakai untuk bahan berbagai barang industri (Harsono dkk., 2018). Baik biji maupun bagian lain dari tanaman dapat dijadikan bahan baku industri kecantikan, farmasi, cat, dan perabot rumah tangga. Bahkan, akhir-akhir ini diketahui bahwa kayu kemiri mempunyai potensi untuk bahan pembuatan batang korek api dan pembuatan kertas. Masyarakat sudah terbiasa menjual biji kemiri dengan mengupas (memecah) biji kemiri sehingga daging biji terpisah dari kulitnya yang hanya terbuang begitu saja sehingga menjadi limbah yang sangat meresahkan masyarakat (Laos dkk., 2016).

Kemiri mempunyai 2 lapis kulit yaitu kulit buah dan cangkang, dari setiap kilogram biji kemiri akan dihasilkan 30\% inti dan 70\% cangkang (Gianyar dkk., 2012). Cangkang kemiri merupakan salah satu produk sampingan dari proses pemanenan buah kemiri. Potensi cangkang kemiri saat ini terus meningkat, dengan semakin luasnya perkebunan kemiri yang terdapat di Indonesia.
Berdasarkan data dari Departemen Pertanian (2009) produksi kemiri nasional terus meningkat dari 99.593 ton pada tahun 2006 menjadi 114.915 ton pada tahun 2009. Produksi kemiri tahun 2009 sebesar 114.915 ton maka dapat dihasilkan $80.440,5$ ton limbah cangkang kemiri yang terdapat di Indonesia (Simbolon dkk., 2015). Dengan meningkatnya jumlah produksi kemiri tentunya juga akan meningkatkan produksi hasil samping berupa cangkang. Saat ini cangkang kemiri belum dimanfaatkan secara optimal dan hanya dibuang sebagai limbah (Pardede dkk., 2013).

Cangkang kemiri menjadi limbah organik yang dapat diuraikan namun dengan teksturnya yang cukup keras membutuhkan waktu untuk menguraikannya secara alamiah, sehingga dilakukan berbagai upaya untuk memanfaatkan limbah cangkang kemiri (Surest dkk., 2008). Limbah cangkang kemiri cukup melimpah dan dapat digunakan sebagai bahan baku pembuatan pupuk. Limbah ini tentunya akan sangat berpotensi bagi masyarakat apabila dimanfaatkan menjadi produk yang mempunyai nilai jual (Hendra \& Darmawan, 2007).

Hendra \& Darmawan (2007) menyatakan bahwa biasanya masyarakat menggunakan dan memanfaatkan cangkang kemiri sebagai arang untuk bahan bakar. Arang pada umumnya mengandung abu sebesar 2-3\%. Berdasarkan hasil penelitian Lempang \& Tikupadang (2013) diperoleh bahwa cangkang kemiri mengandung holoselulosa sebesar $49.22 \%$, lignin sebesar 54.64\%, dan abu sebesar 2.07\%. Analisa unsur dalam kulit dan kayu pohon daun lebar

*Correspondence:

Megawati T. H. Romu

e-mail:megaromu9@gmail.com

(C) 2020 the Author(s) retain the copyright of this article. This article is published under the terms of the Creative Commons Attribution License 4.0, which permits unrestricted non-commercial use, distribution, and reproduction in any medium, provided the original work is properly cited. 
menunjukkan abu dalam kulit biasanya lebih dari $10 \%$ dan sepuluh kali lebih tinggi daripada dalam kayu. Kandungan abu terdiri dari mineral alkali berupa kalsium, kalium, magnesium dan natrium (Manocha, 2003). Mineral tersebut sangat berperan penting dalam mengendalikan pertumbuhan tanaman diantaranya yaitu kalsium dan kalium.

Kalsium merupakan mineral yang diperlukan untuk pertumbuhan dan berfungsinya ujung-ujung akar pada tanaman. Kekurangan ion-ion kalsium dalam tanah akan menyebabkan sumber kalsium yang dibutuhkan tanaman untuk tumbuh semakin terhambat (Suprihatin, 2011). Tanaman memperoleh kalsium dari dalam tanah yang diambil oleh akar dan dikirim ke tunas melalui xilem, kalsium (ion bermuatan positif) dilarutkan dalam air tanah (White, 2001). Sumber kalsium yang terdapat dalam tanah berasal dari batuan kapur (kalsit). Tanah yang berasal dari batuan kapur memiliki kadar kalsium yang tinggi (Rosmarkam \& Yuwono, 2002).

Kalium merupakan mineral yang diperlukan oleh tanaman, terutama ketika proses fotosintesis yaitu untuk mengangkut gula dari daun kejaringan tanaman yang lain dan meningkatkan kekebalan tanaman agar tahan terhadap penyakit. Kalium ditemukan dalam jumlah banyak di dalam tanah, tetapi hanya sebagian kecil yang digunakan oleh tanaman yaitu yang larut dalam air atau yang dapat dipertukarkan. Unsur ini berada bebas di dalam plasma sel dan titik tumbuh tanaman, dapat memacu pertumbuhan tanaman, menambah daya tahan tanaman terhadap serangan hama, penyakit dan kekeringan (Lawani, 1955).

Tulisan ini mendeskripsikan penelitian tentang analisis kandungan kalsium (Ca) dan kalium (K) dalam cangkang kemiri. Sehingga sangat penting diketahui kadar unsur kalsium dan kalium pada cangkang kemiri, agar cangkang kemiri tidak hanya menjadi limbah tetapi dapat dimanfaatkan sebagai bahan baku pembuatan pupuk.

\section{Metode}

Alat yang digunakan dalam penelitian ini adalah cawan penguap, gelas ukur, gelas kimia, pipet tetes, batang pengaduk, kertas saring, oven, labu ukur, gegep, corong pisah, kertas label, tanur, spatula, desikator, neraca digital, botol semprot, dan Spektrofotometer Serapan Atom (SSA) GBC 923 AA, serta lampu katoda untuk logam Ca dan logam $\mathrm{K}$.

Bahan yang digunakan dalam penelitian ini adalah cangkang kemiri (Aleurites moluccana Willd), larutan $\mathrm{HNO}_{3}$ pekat $65 \%$ (Merck), aquades, tissu, dan larutan standar untuk kalsium (Merck) dan kalium (Merck).

\section{Prosedur Penelitian}

\section{Pengambilan Sampel}

Sampel yang digunakan dalam penelitian ini adalah cangkang kemiri yang diperoleh dari
Tamanjeka Kecamatan Poso Pesisir Kabupaten Poso, Sulawesi Tengah.

\section{Preparasi Sampel}

Cangkang kemiri dicuci untuk membersihkan kotoran-kotoran (sisa-sisa daging buah kemiri, kerikil, tanah) dan dipecah menjadi beberapa bagian, diangin-anginkan pada suhu kamar, kemudian ditimbang lalu dikeringkan dengan cara dioven pada suhu $100^{\circ} \mathrm{C}$ selama 2 jam. Cangkang kemiri yang telah dioven didinginkan di dalam desikator dan ditimbang.

\section{Penentuan Kadar Air dan Kadar Abu}

100 gram cangkang kemiri diletakkan dalam cawan penguap, lalu dipanaskan dalam oven pada suhu $105^{\circ} \mathrm{C}$ selama \pm 3 jam, setelah itu didinginkan dalam desikator dan ditimbang, lalu diulangi sampai diperoleh berat konstan. Kemudian ditentukan kadar airnya dengan rumus kadar air (Sudarmadji dkk., 1989).

Cangkang kemiri kering ditimbang diperoleh yaitu 97.40 gram dan diletakkan dalam cawan penguap. Cangkang kemiri kemudian diabukan dengan menggunakan tanur pada suhu $700^{\circ} \mathrm{C}$ selama \pm 3 jam sampai menjadi abu, setelah itu didinginkan dalam desikator dan ditimbang dan ditentukan kadar abunya dengan rumus kadar abu (Sudarmadji dkk., 1989).

\section{Penyiapan Sampel}

0,5 gram sampel abu cangkang kemiri ditambahkan larutan $\mathrm{HNO}_{3}$ pekat $5 \mathrm{~mL}$. Sampel abu kemudian ditambahkan $10 \mathrm{~mL}$ aquades, lalu disaring menggunakan kertas saring hingga terpisah antara filtrat dan residu. Filtrat yang diperoleh diencerkan dengan aquades dalam labu ukur $50 \mathrm{~mL}$ sampai tanda batas.

\section{Analisis Kadar Kalsium dan Kalium}

Larutan sampel cangkang kemiri yang telah diperoleh diambil beberapa $\mathrm{mL}$ kemudian analisis kalsium dan kalium dengan spektrofotometer serapan atom pada panjang gelombang yang berbeda, dimana panjang gelombang yang digunakan yaitu untuk, kalsium $422.7 \mathrm{~nm}$ dan kalium $766.5 \mathrm{~nm}$. Analisis kadar kalsium dan kalium pada sampel dilakukan pengulangan sebanyak 2 kali.

\section{Hasil dan Pembahasan}

\section{Kadar Air dan Kadar Abu pada Cangkang Kemiri}

Kadar air merupakan salah satu parameter bahan pangan yang paling menentukan karakter dan umur simpan. Secara umum, semakin tinggi kadar air suatu bahan, maka akan semakin singkat umur simpan suatu bahan pangan tersebut (Winarno, 2004).

Analisis kadar air bertujuan untuk mengetahui seberapa besar kadar air yang terdapat pada cangkang kemiri yang akan dianalisis. Penentuan kadar air dapat dilakukan dengan beberapa metode yaitu metode pengeringan/oven, metode destilasi, metode desikasi kimia, dan metode khusus (NMR). 
Pada penelitian ini, menggunakan metode pengeringan/oven. Metode pengeringan/oven didasarkan atas prinsip perhitungan selisih bobot bahan sampel sebelum dan sesudah pengeringan. Selisih bobot tersebut merupakan air yang teruapkan dan dihitung sebagai kadar air bahan, air di dalam bahan pangan ada dalam tiga tipe yaitu air lapisan tunggal (water monolayer), air lapisan banyak (water multilayer) dan air bebas. Pada pengukuran kadar air bahan pangan, air yang terukur adalah air lapisan banyak (water multilayer) dan air bebas, karena kedua tipe air tersebut mudah dihilangkan dengan proses pengeringan (Andarawulan dkk., 2011). Hasil penelitian ini menunjukkan cangkang kemiri mempunyai kadar air sebesar $2.59 \%$.

Penentuan kadar abu dalam suatu sampel langkah pertama dalam analisis ini yaitu preparasi sampel. Pada tahap preparasi sampel harus didekstruksi terlebih dahulu. Proses destruksi bertujuan untuk menghilangkan, merombak dan memutuskan ikatan-ikatan senyawa organik yang terdapat dalam sampel sehingga yang tinggal hanya senyawa anorganik saja. Cara yang biasa dilakukan adalah pengeringan dan pengabuan. Pemilihan tersebut tergantung pada sifat zat organik dalam bahan mineral yang akan dianalisis (Maria, 2009).

Menurut Lubis (2014) ada dua prosedur yang umum digunakan untuk mendestruksi bahanbahan organik dalam sampel, yaitu dengan oksidasi basah (wet oksidation) dan pengabuan kering ( $d r y$ ashing). Dalam penelitian ini dekstruksi sampel menggunakan prosedur pengabuan kering.

Kadar abu suatu sampel padat perlu ditentukan untuk melakukan estimasi berapa banyak unsur-

Tabel 1 Data kadar kalsium (Ca) dalam Cangkang Kemiri (Aleurites moluccana Willd)

\begin{tabular}{ccc}
\hline \multirow{2}{*}{ Perlakuan } & $\begin{array}{c}\text { Konsentrasi Larutan } \\
\text { Sampel }(\mathrm{mg} / \mathrm{L})\end{array}$ & $\begin{array}{c}\text { Kadar Kalsium } \\
(\%)\end{array}$ \\
\hline I & 8.197 & 0.383 \\
II & 10.584 & 0.247 \\
Rata-rata & $9.390 \pm 1.68$ & $0.315 \pm 0.09$ \\
\hline
\end{tabular}

Tabel 2 Data kadar kalium (K) dalam Cangkang Kemiri (Aleurites moluccana Willd)

\begin{tabular}{ccc}
\hline \multirow{2}{*}{ Perlakuan } & $\begin{array}{c}\text { Konsentrasi Larutan } \\
\text { Sampel }(\mathrm{mg} / \mathrm{L})\end{array}$ & $\begin{array}{c}\text { Kadar Kalsium } \\
(\%)\end{array}$ \\
\hline I & 2.138 & 0.099 \\
II & 1.748 & 0.081 \\
Rata-rata & $1.943 \pm 0.27$ & $0.090 \pm 0.01$ \\
\hline
\end{tabular}

Analisis kadar kalsium dan kalium pada sampel dilakukan sebanyak 2 kali. Hasil yang diperoleh pada penelitian ini adalah rata-rata konsentrasi kalsium dalam larutan sampel $9.390 \pm 1,68 \mathrm{mg} / \mathrm{L}$ dan rata-rata kadar kalsium pada sampel $0.315 \pm$ $0.09 \%$. Sedangkan rata-rata konsentrasi kalium dalam larutan sampel $1.943 \pm 0.27 \mathrm{mg} / \mathrm{L}$ dan ratarata kadar kalium pada sampel $0.090 \pm 0.01 \%$. Kadar kalsium dan kalium yang diperoleh dalam penelitian ini jika dibandingkan berdasarkan hasil yang diperoleh dengan literatur, keduanya memiliki perbedaan. Kadar kalsium yang diperoleh dalam unsur anorganik atau mineral yang terkandung dalam sampel. Kadar abu dapat dicari dengan cara mengabukan sampel yang akan dianalisis. Sampel diabukan dengan menggunakan tanur (furnace) pada suhu $700^{\circ} \mathrm{C}$ selama \pm 3 jam sampai menjadi abu yang berwarna keabu-abuan yang menandakan bahwa pengabuan sempurna. Hal ini berfungsi untuk mengoksidasi semua zat organik pada suhu tinggi dan untuk mempercepat dan menyempurnakan proses destruksi. Setelah sampel telah menjadi abu, sampel ditimbang. Hasil yang diperoleh pada penentuan kadar abu pada sampel cangkang kemiri yaitu sebesar 4.69\%.

\section{Analisis Kadar Kalsium (Ca) dan Kalium (K) dalam sampel Cangkang Kemiri}

Pengukuran konsentrasi mineral dapat dilakukan dengan menggunakan alat SSA. Cuplikan atau sampel yang akan diukur haruslah berupa larutan. Oleh karena itu sampel abu yang diperoleh dari proses pengabuan dilarutkan dengan $\mathrm{HNO}_{3}$ pekat. Penambahan $\mathrm{HNO}_{3}$ pekat dalam proses pengabuan bertujuan untuk mengoksidasi semua karbon dan melarutkan garam-garam yang terdapat dalam sampel. Larutan $\mathrm{HNO}_{3}$ pekat berfungsi untuk melarutkan logam-logam yang terdapat di dalam sampel, karena $\mathrm{HNO}_{3}$ pekat merupakan pelarut logam yang universal dan dapat menstabilkan logam-logam yang akan dianalisis (Hidayati, 2011).

Analisis konsentrasi kadar kalsium dan kalium dalam sampel cangkang kemiri dengan menggunakan SSA disajikan dalam Tabel 1 dan 2 . penelitian yang dilakukan oleh Lempang \& Tikupadang (2013) tentang aplikasi arang aktif tempurung kemiri sebagai komponen media tumbuh semai melina, untuk arang aktifnya memiliki kadar $\mathrm{CaO}$ sebesar $0.86 \%$ dan kadar $\mathrm{K}_{2} \mathrm{O}$ sebesar $0.71 \%$. Adanya perbedaan hasil yang diperoleh dari penelitian ini dengan literatur disebabkan karena pada literatur sampel yang dianalisis bukan dalam bentuk unsur murni, tetapi sampel tersebut dalam bentuk unsur hara yang telah menyatu dengan media tanam (tanah). 
Perbedaan kadar kalium dan kalsium darì sampel cangkang kemiri juga disebabkan karena adanya perbedaan lingkungan, tempat tumbuh, keadaan tanah dan cuaca, sehingga mempengaruhi kandungan nutrisi organik di dalamnya. Apabila di sekitar tempat tumbuhnya banyak terdapat kalsium, maka pada buah yang dihasilkan akan terdapat banyak kalsium. Kekurangan ion-ion kalsium dalam tanah akan menyebabkan sumber kalsium yang dibutuhkan tanaman untuk tumbuh semakin terhambat (Fitriani dkk., 2012).

Kalsium (Ca) merupakan unsur hara semi makro yang dibutuhkan tanaman. Di dalam tanah, ketersediaan unsur hara kalsium dalam bentuk kation yang dapat dipertukarkan. Kadar kalsium yang tinggi dalam tanah umumnya berpengaruh terhadap kemasaman tanah. Kehadiran kalsium menyebabkan kemasaman tanah menjadi rendah atau $\mathrm{pH}$ tanah tinggi. Oleh karena itu, pengelolaan hara kalsium melalui pemupukan kapur (pengapuran) di lapangan sering diupayakan selain untuk mencukupi kebutuhan kalsium tanaman juga digunakan untuk meningkatkan $\mathrm{pH}$ tanah. Kalsium berperan sebagai nutrisi tanaman yang diperlukan untuk pertumbuhan dan perkembangan khususnya akar dan tunas (Tuteja \& Mahajan, 2007). Gejala tanaman kekurangan $\mathrm{Ca}$ yaitu terhambatnya pertumbuhan pucuk (titik tumbuh), kemudian pertumbuhan tanaman kerdil dan mati (Baker \& Pilbean, 2006).

Menurut Tuma dkk., (2004) kalium dalam tumbuhan berada pada konsentrasi yang tinggi pada bagian batang tanaman daripada bagian daun. Kalium sendiri merupakan hara esensial yang diperlukan dalam jumlah banyak oleh tanaman (Supriyadi, 2009). Selanjutnya Ruhnayat (1995) menyatakan bahwa fungsi kalium yaitu dapat meningkatkan efisiensi fotosintesis. Kalium juga berperan memperkuat tubuh tanaman, agar daun, bunga dan buah tidak mudah gugur. Kalium juga sebagai sumber kekuatan bagi tanaman dalam menghadapi kekeringan dan penyakit. Tanaman yang cukup akan kalium dapat mempertahankan kandungan air dalam jaringannya, karena mampu menyerap lengas (kelembaban) dari tanah dan mengikat air sehingga tanaman tahan terhadap cekaman kekeringan (Subandi, 2013).

\section{Kesimpulan}

Kadar kalsium rata-rata pada cangkang kemiri yaitu $0.315 \pm 0.09 \%$ serta kadar kalium ratarata pada cangkang kemiri yaitu $0,09 \pm 001 \%$.

\section{Ucapan Terima kasih}

Penulis mengucapkan terima kasih kepada laboran Laboratorium Kesehatan Daerah Provinsi Sulawesi Tengah dan semua pihak yang banyak membantu penulis dalam menyelesaikan penelitian ini.

\section{Referensi}

Andarwulan, N., Kusnandar, F., \& Herawati, D. (2011). Analisis pangan. Jakarta: Dian Rakyat.
Baker, A. V., \& Pilbean, D. J. (2006). Hunger sign in crops. in D. J. Merhaut. Handbook of plants nutrion (p. 117). Florida, USA: CRC Press.

Departemen Pertanian. (2009). Kemiri (Candlenut). statistik perkebunan Indonesia (the crops estate statistic of Indonesia) 2007-2009. Jakarta: Direktorat Jenderal Perkebunan.

Fengel, D., \& Wegener, G. (1995). Kayu: Kimia, ultrastruktur, reaksi-reaksi. Yogyakarta: Gadjah Mada University Press.

Fitriani, C. N., Walanda, D. K. ,\& Rahman, N. (2012). Penentuan kadar kalium (K) dan kalsium $(\mathrm{Ca})$ dalam labu siam (Sechium edule) serta pengaruh tempat tumbuhnya. Jurnal Akademika Kimia, 1(4), 174-180.

Gianyar, G. B. I., Nurchayati, \& Padang, A. Y. (2012). Pengaruh persentase arang tempurung kemiri terhadap nilai kalor briket campuran biomassa ampas kelapa-arang tempurung kemiri. Jurnal Dinamika Teknik Mesin, 2(2), 6774.

Harsono, D., Yusran, \& Umar, H. (2018). Pengaruh perbandingan tanah dan serbuk arang tempurung kemiri sabagai media tumbuh terhadap pertumbuhan semai kemiri (Aleuritas moluccana Willd). Jurnal Warta Rimba, 6(1), 3947.

Hendra, D., \& Darmawan, S. (2007). Sifat arang aktif dari tempurung kemiri (The properties of activated charcoal from candlenut shell). Jurnal Penelitian Hasil Hutan, 25(4), 291-302.

Hidayati, S. N. (2011). Kadar kalsium (Ca) dan kalium (K) pada sayur kangkung (Ipomea reptans) yang tumbuh di kota Palu. Skripsi Tidak Diterbitkan. Palu: Universitas Tadulako.

Laos, E. L., Masturi, \& Yulianti, I. (2016). Pengaruh suhu aktivasi terhadap daya serap karbon aktif kulit kemiri. Prosiding Seminar Nasional Fisika (SNF), 135-140.

Lawani, M. (1995). Budidaya dan penanganan pascapanen. Yogyakarta: Kanisius.

Lempang, M., \& Tikupadang, H. (2013). Aplikasi arang aktif tempurung kemiri sebagai komponen media tumbuh semai melina. Jurnal Penelitian Kehutanan Wallacea, 2(2),121-137.

Lubis, D. A. (2014). Akumulasi logam timbal (Pb) dan tembaga (Cu) pada ikan kuniran (Upeneus sulphureus) dari perairan estuaria teluk Palu Sulawesi Tengah. Skripsi Tidak Diterbitkan. Palu: Universitas Tadulako.

Maria, S. (2009). Penentuan kadar logam besi (Fe) dalam tepung gandum dengan cara destruksi basah dan kering dengan spektrofotometri serapan atom sesuai standar nasional Indonesia (SNI) 0137512006. Skripsi Tidak Diterbitkan. Medan: Universitas Sumatra Utara.

Manocha, S. (2003). Porous carbons. Journal Sadhana, 28(1-2), 335-348. 
Pardede, A., Ratnawati, D., \& Martono, A. (2013). Ekstraksi dan karakterisasi pektin dari kulit kemiri (AIIeurites mollucana Wiild). Media Sains, 5(1), 1-6.

Rosmarkam, \& Yuwono, W. N. (2002). Ilmu kesuburan tanah. Yogyakarta: Kanisius.

Ruhnayat, A. (1995). Peranan unsur hara kalium dalam meningkatkan pertumbuhan, hasil dan daya tahan tanaman rempah dan obat. Jurnal Penelitian dan Pengembangan Pertanian, 14(1),10-15.

Siallagan, Y. A., Daulay, B. S., \& Harahap, A. L. (2012). Pemecahan cangkang kemiri (Alleuirites mollucana) menggunakan sistem ripple mill dengan berbagai suhu perendaman. Jurnal Rekayasa Pangan dan Pertanian, 1(1), 70-76.

Simbolon, L. I., Sucipto, T., \& Hartono, R. (2015). Pengaruh ukuran partikel dan komposisi semenpartikel terhadap kualitas papan semen dari cangkang kemiri (Aleurites Moluccana Willd). Peronema Forestry Science Journal, 4(1), 1-8.

Subandi. (2013). Peran dan pengelolaan hara kalium untuk produksi pangan di Indonesia. Jurnal Pengembangan Inovasi Pertanian, 6(1), 110.

Sudarmadji, S., Haryono, B. \& Suhardi. (1989). Analisa bahan makanan dan pertanian. Yogyakarta: Liberty.

Sunanto, H. (1994). Budidaya kemiri, komoditas ekspor. Yogyakarta: Kanisius

Suprihatin. (2011). Proses pembuatan pupuk cair dari batang pohon pisang. Jurnal Teknik Kimia, 5(2), 429-433.

Supriyadi, S. (2009). Status unsur-unsur basa $\left(\mathrm{Ca}^{2+}\right.$, $\mathrm{Mg}^{2+}, \mathrm{K}^{+}$, and $\mathrm{Na}^{+}$) di lahan kering Madura. Agrovigor, 2(1), 35-41.

Surest, H. A., Kasih, F. A. J., \& Wisanti, A. (2008). Pengaruh suhu, konsentrasi zat aktivator dan waktu aktivasi terhadap daya serap karbon aktif dari tempurung kemiri. Jurnal Teknik Kimia, 2(15), 17-22.

Suwarto, Octavianty, Y., \& Hermawati, S. (2014). Top 15 tanaman perkebunan. Jakarta: Penebar Swadaya.

Tuma, J., Skalicky, M., Tumova, L., Blahova, P., \& Rosulkova, M. (2004). Pottasium, magnesium, and calcium content in individual parts of Phaseolus vulgaris L. plant as related to potassium and magnesium nutrition. Plant, Soil and Environment, 50(1), 18-26.

Tuteja, N., \& Mahajan, S. (2007). Calcium signaling network in plants. Journal of Plant Signaling \& Behavior, 2(2), 79-85.

White, P. (2001). The pathways of calcium movement to the xylem. Journal of Experimental Botany, 52(358), 891-899.

Winarno, F. G. (2004). Kimia pangan dan gizi. Jakarta: PT. Gramedia Pustaka Utama. 